\title{
Carnatal: A criatividade como ferramenta propulsora do turismo de eventos
}

\author{
Carnatal: Creativity as a tool to propel events tourism
}

\section{Gildygleide Cruz de Brito}

Mestre em Turismo pelo Programa de Pós-Graduação em Turismo (PPGTUR) da Universidade Federal do Rio Grande do Norte - UFRN, Natal/RN, Brasil

E-mail: gildygleide@hotmail.com

\section{Lissa Valéria Fernandes Ferreira}

Professora Adjunta do Departamento de Turismo da Universidade Federal do Rio Grande do Norte - UFRN, Natal/RN, Brasil

E-mail: lissaferreira.iadb@yahoo.es 


\section{RESUMO}

O artigo traz reflexões sobre a relação entre os elementos criativos utilizados na projeção do Carnatal, assim como os identificados na realização do evento e sua potencialidade como produto turístico. Aponta o processo de estímulo da criatividade dos indivíduos que compõem a Destaque Promoções, empresa organizadora do evento, e identifica os componentes capazes de proporcionar uma nova roupagem ao Carnatal, trazendo assim propostas inovadoras para sanar problemas recorrentes, assim como revestir a festividade com uma atmosfera intangível e repleta de subjetividade. Destaca o processo evolutivo do evento e as inovações incrementais aplicadas, da mesma maneira que contextualiza a empresa organizadora do evento. Apresenta dados que corroboram com a premissa do Carnatal como importante produto turístico da cidade de Natal/RN. Conclui que o turismo de eventos muito se beneficia com a realização anual do evento, todo o trade turístico local é atingido de forma positiva, à marca da cidade Natal é disseminada, o que leva a entender que o Carnatal desponta e se mantém não apenas como parte de um produto turístico maior, mas revela-se como o próprio.

Palavras-chave: Micareta. Carnatal. Turismo de Eventos. Criatividade.

\section{ABSTRACT}

The article brings up reflections about the relationship between the creative elements used in the Carnatal projection, as well as those identified in the accomplishment of the event and its potential as a tourism product. It points out the process of stimulating the creativity of the individuals that make up Destaque Promociones, the company that organizes the event, and identifies the components capable of providing a new look to Carnatal, thus bringing innovative proposals to remedy recurring problems, as well as clothe the festival with an intangible atmosphere and full of subjectivity. It highlights the evolutionary process of the event and the incremental innovations applied, in the same way that contextualizes the company that organizes the event. It presents data that corroborate with the premise of Carnatal as an important tourist product of the city of Natal / RN. It concludes that event tourism greatly benefits from the annual realization of the event, all the local tourist trade is reached in a positive way, the brand of the city Natal is widespread, which leads to understand that the Carnatal rises and remains not only as part of a larger tourist product, but reveals itself.

Keywords: Micareta. Carnatal. Event Tourism. Creativity. 


\section{INTRODUÇÃO}

Há tempos a relação entre eventos e turismo vem sendo estabelecida de modo a despertar um novo olhar para essa conjuntura. Pesquisas são realizadas com intuito de desbravar as mais distintas nuances e possibilidades dessa conexão, assim como os resultados possíveis.

A aproximação entre tais atividades é concretizada a partir do interesse mútuo de complementariedade, ou seja, além de fortalecer suas potencialidades, preenche lacunas encontradas em suas individualidades e assim revestir-se como um produto mais competitivo (Connel, Page \& Meyer, 2015).

Devido às características peculiares desse processo, e aí se ressalta a fundamentalidade de transformar cada evento em um elemento crucial do produto turístico, repousa a complexidade da criação, do planejamento e da execução desse.

Conceber um evento exige o orquestramento de ações, o alinhamento de estratégias, a definição de metas, a coordenação de decisões e a constante avaliação de seu progresso, com vistas a minimizar as falhas e, caso essas surjam, propor soluções rápidas (Britto \& Fontes, 2013).

Diante do amplo universo do turismo, dos anseios de uma demanda e da competitividade de mercado, o segmento do turismo de eventos busca dispor de distintas alternativas capazes de captar o turista potencial, convertendo-o a um turista real. Assim, com uma perspectiva voltada a demanda, permite maior espaço para a criação, inovação e crescimento a custos e riscos significativamente mais baixos. (Getz, 2016).

Dentro desse universo de eventos planejados com a finalidade de promover um destino turístico, os festivais musicais emergem como uma alternativa representativa que há muito vem sendo utilizada por várias localidades. Bowen e Daniels (2005) apontam os festivais como eventos especiais únicos, em que a música é o tema central e onde geralmente inúmeras performances de diferentes artistas estão envolvidas. Além disso, quase sempre incluem atividades e diversões, além da música em si. Devido a essa particularidade, os festivais de música podem atrair pessoas por uma variedade de razões.

Como exemplo de festival bastante disseminado no Brasil e em terras estrangeiras, as micaretas constituem-se como um campo capaz de gerar relações econômicas e sociais relevantes. Tal festividade revela-se como destaque no gênero de festas populares na Bahia e em todo o nordeste brasileiro e que, pela dimensão que possui, chama a atenção de entidades públicas e privadas. A lógica da festa ultrapassa a percepção simplista e encontra no cerne da 
organização uma rede de entidades que reinventam o evento a cada edição idealizada (Pinto \& Jesus, 2010).

O Carnatal, micareta da cidade de Natal, Rio Grande do Norte, apresenta peculiaridades consideráveis, uma vez que, seu histórico o remete como a primeira micareta realizada em uma capital distinta de Salvador, berço desse evento. A sua manutenção diante dos entraves surgidos no decorrer dos tempos, o fortalecimento de sua permanência a frente de nicho que, na última década, sofreu um desgaste natural e sua capacidade de promover o deslocamento de uma demanda turística a capital potiguar, instiga a busca pelo entendimento do uso da criatividade como ferramenta de transformação do Carnatal e na conversão do mesmo como uma parte significativa na composição do produto turístico potiguar.

Vista como uma competência multifacetada e capaz de promover a inovação, e evolução, almejada na organização dos eventos, a criatividade vem ganhando notoriedade, como uma força propulsora e renovada, num mundo globalizado e competitivo. Fato é que todas as esferas da sociedade se beneficiam com o desenvolvimento e a aplicabilidade dessas ações imperativas a contemporaneidade.

No campo econômico, as beneficies são mais visíveis, já que a criatividade convertida em inovação é capaz de gerar um diferencial competitivo para pequenas organizações a grandes nações. Pesquisas são desenvolvidas com o propósito de colaborar na elucidação do cenário da inovação e, assim, apresentar estratégias capazes de nortear ao caminho da competitividade e do consequente crescimento econômico.

O estudo da criatividade agrega um diferencial à forma de realizar eventos, especificamente micaretas, pois aponta a possibilidade de evolução contínua e possibilita acompanhar e adaptar-se aos interesses mutáveis de uma demanda cada vez mais exigente que busca produtos intangíveis em prol da experimentação de vivências ímpares.

Poder compreender como a criatividade é utilizada nas micaretas e convertida em beneficies ao turismo de eventos de um destino permite trazer à tona estratégias que norteiem a elaboração de respostas novas e úteis, promovendo um delineamento para ações futuras.

Desse modo, torna-se premente a antecipação de tendências, por meios criativos e inovadores, nos eventos abarcados pelo turismo, facilitado, dessa forma, a geração de valor a partir da produção de experiências diferenciadas. 


\section{REFERENCIAL TEÓRICO}

Eventos à Luz do Turismo

A discussão em torno da presente temática vem evoluindo gradativamente, voltando seu foco as vantagens percebidas, como também as possíveis intervenções negativas, de modo que a identificação de tais elementos possibilitará estratégias que aperfeiçoem as ações positivas e trabalhem os efeitos negativos, eliminando-os ou articulando-os aos interesses da sociedade.

Getz e Page (2016) apontam que o turismo de eventos evoluiu para uma ciência mais social e trazem a gestão de eventos e o turismo de eventos como os principais fundamentos da pesquisa em eventos. O turismo de eventos mostra-se como um segmento do turismo por revelar-se estreitamente ligado à utilização dos equipamentos turísticos de uma localidade por ocasião de um evento, sendo esse o motivo maior para a viagem.

Essa motivação inicial acaba por resultar num incremento na atividade turística local, pois, de acordo com Britto e Fontes (2013), um evento capaz de reunir uma demanda de distintas localidades incentiva a realização de uma viagem, que, por sua vez, aproveita-se da ocasião para a efetivação de passeios, de compras, de visitação a pontos turísticos, promovendo, assim, a utilização da infraestrutura básica e turística de uma cidade.

Ademais, Beni (2003) aponta que a realização de eventos, no campo do turismo, atua como uma ferramenta promotora da atratividade turística equilibra a sazonalidade, movimenta uma demanda em locais de pouca atratividade e amplia o uso da estrutura básica e turística da localidade receptora.

Derrett (2003) complementa que a promoção de eventos é capaz de estender temporadas turísticas, de ampliar o ápice dessas ou, até mesmo, de incluir uma nova temporada a um circuito turístico. Além disso, os eventos possuem um papel fundamental na elaboração de uma imagem positiva do destino, pois concilia atrações adicionais e valoriza o local de manifestação turística (Getz, 1997).

Os benefícios ocasionados pela realização de eventos e a sua utilização como produto turístico são notórios, tanto que cada vez mais localidades optam por incrementar a modalidade, seja através da captação de megaeventos, pela utilização de eventos de caráter cultural, religioso, eventos organizacionais ou acadêmicos, shows, ou qualquer evento capaz de incrementar uma demanda turística.

Nesse cenário, observa-se que muitos eventos começam a ser elaborados como intuito de gerar benefícios, tais como entretenimento, socialização e escapismo, ocasionando, assim, 
uma segmentação de mercado. Com vistas a uma demanda mais exigente, a experiência passou a ser o objetivo buscado pelas promotoras de eventos, para, dessa forma, despertar o interesse de uma viagem.

As experiências oferecidas pelos eventos passaram a ser o fenômeno central do turismo, capaz de movimentar uma demanda crescente, criando significados ao ato de viajar. Muitas são as possibilidades de experiências em eventos potenciais, passado pela diversão, a folia e o entretenimento do carnaval ou outra festividade, à espiritualidade de uma peregrinação religiosa, a aprendizagem, apreciação estética ou o fomento a criatividade e ao comércio (Getz \& Page, 2016).

O conceito de experiência é embasado em três pilares inter-relacionados: o que as pessoas estão fazendo (ativo), quais suas emoções (afetivo) e qual sua percepção (cognitivo). Observa-se que a experiência é empreendida a partir das necessidades, das motivações, da atitude e das expectativas trazidas ao evento, através da própria experiência de vida real, incluindo significados e comportamentos futuros (Getz \& Page, 2016).

Csikszentmihalyi (1990) apresenta que a necessidade de um fluxo de experiências e a efetivação destas pode ser algo que o designer do evento quer atingir para proporcionar o máximo envolvimento e a alta inclinação à experimentação. Assim, [...] aumenta a possibilidade das pessoas entrarem em um local específico do evento por determinados períodos de tempo, para se evolverem em atividades que são fora do comum e terem experiências que transcendem o comum e oferecidas apenas para o viajante ou o frequentador do evento (Getz \& Page, 2016, p. 608).

Desse modo, muitos designers estão interessados na possibilidade de moldar, de programar, de configurar e de gerir o evento, de forma a aumentar ou a diminuir as respostas emocionais e, assim, afetar tanto a satisfação quanto o comportamento.

Diante dessa intangibilidade gerada pelo anseio individual de experienciar, constata-se que o futuro do turismo de eventos ainda é algo difícil de definir. Getz e Page (2016) apresentam um norte às pesquisas que estão por vir, questionando o que pode acontecer, o que é mais provável acontecer e o que preferem que aconteça, fornecendo, portanto, uma amplitude aos estudos futuros.

Em geral, com a forte tendência voltada à pessoa, acredita-se que a conexão criatividade e eventos têm muito a colaborar para a concretização de experiências únicas e memoráveis e, por meio do desenvolvimento de pesquisas, auxiliará a criar caminhos inovadores para despertar o constante interesse de uma demanda. 
A Micareta: Um Evento Palco da Criatividade

A micareta é um tipo de evento que permeia a tipologia cultural e a de entretenimento. Sua face cultural está atrelada a sua essência e a construção através dos valores sociais e econômicos. Moital (2012) aponta que esses carnavais fora de época são conhecidos pela tentativa de recriar o carnaval de Salvador em menor escala e que levam consigo características próprias e uma representação latente da cultura baiana.

Percebe-se, também, que há uma interpolação de culturas, hábitos e modos de vida, que faz com que esse evento conjugue a cultura baiana a traços peculiares de cada localidade em que acontece e forneça uma roupagem diferenciada a cada edição. Sua posição como evento de entretenimento também é fortalecida a partir do objetivo do evento. As pessoas que se predispõem a participar de micaretas buscam por diversão, alegria e, como mostra Moital (2012), esses eventos são orientados para celebrar a vida, para promover a felicidade e para desafiar os valores e as regras preconcebidas.

Para entender melhor a logística dessa modalidade eventos, faz-se, então, importante atentar ao seu surgimento e aos motivos que elevaram sua importância, sua expansão, ao seu ápice e a situação atual, assim como entender como a criatividade se manifesta em suas realizações.

A micareta é um evento que se enquadra em uma categoria de festividade e que enaltece a cultura popular. Trata-se, portanto, de uma celebração, que segundo Gaudin (2000) tem sua origem atrelada a duas festas: uma denominada 'serração da velha'; e a outra possui uma nomenclatura fracesa, mi- carême.

A serração da velha é uma festa ibérica que acontecia na Quaresma. Seu símbolo era uma velha senhora feia e magra que representava o tempo de ausência de alimentos na península ibérica. Já a mi-carême, uma festa de origem francesa, chegou ao Brasil somente no século XX. Nessa época, a vida cultural da República sofria influências de Paris, que importava no período do carnaval o lance-parfum Gaudin (2000).

Tais eventos nunca eram confundidos com o carnaval, cada qual tinham suas características e ocorriam separadamente. Mas, em 1914, a mi-carême foi celebrada como se fosse carnaval, ou melhor, como um carnaval fora de época. Esse fato aconteceu em Salvador/BA e foi idealizado pelo clube carnavalesco soteropolitano Fantoches de Euterpe, que trouxe a proposta de realizar um segundo carnaval do ano Gaudin (2000).

O evento foi bem aceito pela população e muito criticado pelas autoridades católicas, por ocorrer no domingo de páscoa. Entre o sucesso e as perseguições, a mi-carême foi protagonista, durante muitos anos, na capital baiana, até que, através das manifestações 
contrárias da igreja, a festa foi transferida para o domingo subsequente ao de Páscoa, o que fez a celebração perder adeptos. Em 1935, houve um plebiscito para definição de um novo nome, emergindo, aí, o termo micareta, mistura de mi-carême e careta. Em 1942, ocorreu a última edição dessa celebração Gaudin (2000).

$\mathrm{Na}$ década de trinta, por ser o carnaval tão majestoso na capital baiana, acabou por atrair foliões de outros destinos da Bahia, resultando um enfraquecimento do carnaval dessas cidades. Feira de Santana foi uma das cidades mais impactadas, devido a sua proximidade a Salvador. Visando superar a baixa demanda desse período, Feira de Santana aderiu à micareta em 1937, sendo, então, a primeira cidade fora de Salvador a obter sucesso com a festividade Gaudin (2000).

Da data inicial até 1951, a festa era realizada num formato tradicional constituído por bailes nos clubes sociais da cidade, desfiles de carros alegóricos, mascarados, desfile de cordões que evoluíram e passaram a ser puxados por charangas, blocos e batucadas. Tudo foi transformado a partir da introdução do trio elétrico, dando, assim, uma nova roupagem ao evento Gaudin (2000).

Surge, portanto, uma nova era para as micaretas. Dodô e Osmar inserem duas invenções, a guitarra baiana e o veículo sonoro, que resultaram em, pelo menos, duas grandes mudanças: estendeu o período da festividade da Páscoa até o São João e multiplicou o número de micaretas pelo interior da Bahia, Gaudin (2000).

Constata-se que o trio elétrico foi o responsável pela origem de diversas micaretas pelo território baiano, estreitando a relação entre os dois, uma vez que o dinheiro arrecadado com as festividades promovia a modernização dos trios.

A micareta modificou-se aos poucos e assumiu cada vez mais semelhanças com o carnaval de Salvador. Atualmente, a festa "micaretesca" ocorre fortemente no interior da Bahia e é possível brincar o carnaval de Salvador em outras épocas do ano e fora dali (Xavier \& Maia, 2010).

A parceria estendeu-se por muitos anos, até que a própria modernização foi responsável por uma crise de financiamento, já que o investimento nesse veículo passou a ser exorbitante. O final da década de sessenta e meados da de setenta foi o ápice da crise entre trios elétricos, para as micaretas e até para o carnaval de Salvador.

A privatização do espaço festivo foi o responsável por cessar a crise e o que era antes aberto e público, passou, então, a ser pago pelo folião que desejava participar. Os blocos passaram a ser os contratantes dos trios e adquiriram uma estrutura organizacional. Em 1978, 
o bloco Camaleão estruturou-se e passou a ser exemplo aos demais que se inseriram no mercado do carnaval de Salvador e das micaretas.

Outro ponto a ser destacado como pertinente na consolidação das micaretas ocorreu na década de noventa, quando um grande interesse, nacional e internacional, pela cultura baiana, emergiu. Esse interesse acabou por propiciar outra vertente econômica, o turismo, que causou uma nova descoberta do nordeste brasileiro.

Um número crescente de turistas passou a ir ao carnaval de Salvador movimentando intensamente todo o trade turístico, além de trazer uma demanda crescente aos blocos. $\mathrm{O}$ produto Bahia-festa ganha força e visibilidade no mercado, fazendo com que a festa passasse a transbordar seus limites (Gaudin, 2000).

Esse incremento econômico e a visibilidade dada à Bahia através do evento fez com que outros destinos do nordeste brasileiro atentassem para o sucesso do evento, como bem coloca Gaudin (2000, p. 61):

[...] o carnaval de trio despertou nos outros estados da região nordeste o interesse tanto das autoridades públicas como da iniciativa privada: os primeiros queriam entrar na _onda baiana“ e atrair turistas para seus estados, enquanto os empresários se interessavam pela nova forma de negócio que representava a organização de festas na base bloco empresa.

Com base no exposto, observa-se que no período de 1990 e 1993 se inicia o processo de expansão das micaretas para além das fronteiras do estado baiano. O desfile dos trios elétricos embalados por bandas de axé, mistura de ritmos e danças baianas foi importado da Bahia por entidades públicas e privadas.

A Micarande, micareta de Campina Grande/Paraíba foi o primeiro modelo de festa, copiado das micaretas baianas, a ser implementada em território fora da Bahia. Foi um projeto criado pelo Departamento Municipal de Turismo do município e acabou por ser o estreante dessa modalidade.

No ano seguinte, em 1991, surge o Carnatal na capital norte-rio-grandense. O evento passou a fazer parte do projeto Natal em Natal e tinha o propósito de atrair turistas à cidade de Natal num período de início de alta temporada. Essa passou a ser a primeira micareta realizada em outra capital e promovida por uma empresa privada.

Em Fortaleza, o evento ocorreu no ano de 1992 e foi implementado por um jovem empresário que o inseriu no período de eventos pré-carnavalescos. No mesmo ano, outras duas micaretas passaram a fazer parte do calendário nacional.

Em Aracajú, inicialmente chamado de 'Suas férias com amor', e depois passou a ser chamado de 'Pré-Cajú'. E, na capital do Brasil, Brasília, emergiu a 'Micarecandanga' que, 
apesar das dificuldades encontradas nos dois primeiros anos, consolidou-se nos anos seguintes (Gaudin, 2000).

Já em 1993, nasce na capital pernambucana, o 'Recifolia'. Mais uma micareta organizada pela prefeitura local. Ressalta-se que as micaretas exportadas da Bahia se apresentam com uma nova configuração e o que era uma celebração diversificada, passou a limitar-se ao desfile de blocos atrás dos trios elétricos.

O sucesso foi efetivando-se nesse período inicial e mercado de venda de abadás, vestimenta utilizada para adentrar nos blocos, fortalecia-se gradativamente. Gaudin (2000, p. 63) diz que:

Os turistas afluíam, o volume dos negócios aumentava e o sucesso não era somente
comercial, como também de público: centenas de milhares de foliões não pagantes,
os chamados pipocas', juntavam-se ao longo das avenidas dos desfiles para ver as
bandas baianas passarem. A tal ponto que a micareta se tornou o maior evento
cultural do ano, sobrepujando o próprio carnaval, as festas juninas ou qualquer outra
festa.

Após 1993, houve um crescimento considerável das micaretas pelo Brasil. Em 1994, contabilizavam 23 eventos desse tipo; já em 1995, passou a ser 29 e, depois dessa data, ficou difícil registrar o número oficial de micaretas a surgir pelo país, uma vez que, além das grandes capitais, as pequenas cidades interioranas aderiram ao evento também, além da efetivação interacional, o carnabeach, que ocorreu em 1997, em Miami/Estados Unidos.

Nos últimos dez anos, as micaretas adentraram num processo de crise justificado por diversos fatores. O primeiro deles é a própria crise do axé music, conjunto de ritmos que por muitos anos manteve-se popular e ao celebrar seus trinta anos de existência, em 2015, adentraram num processo de declínio depois de um determinado tempo de sucesso. Vale ressaltar que esse tipo de música se manteve por um tempo acima do que é normalmente visto e ainda se mantem, mesmo que com uma incidência menor, no gosto popular.

Outro fator que age diretamente sobre as micaretas é a crise econômica atual, que acaba por diminuir a demanda diante de uma limitação de recursos. Algo que vem se propagando também está relacionada a postura dos empresários do axé music, que passaram a ser vistos com manipuladores comerciais, aqueles que transformaram os traços culturais do axé, tornando-os um espetáculo desconforme da realidade. A própria comunidade promotora do carnaval de Salvador e, consequentemente, das micaretas, passaram a ser excluídas do processo, beneficiando apenas os detentores de um alto poder aquisitivo, capazes de pagar valores exorbitantes para participar do evento. 
Diante desse cenário, muitos foram os eventos renomados que saíram do calendário nacional, dentre tais destaca-se: a Micarande, o Recifolia, a Micaracandanga, o Pré-Cajú, assim, apenas 18 micaretas mantiveram-se no mercado.

Diante desse impasse, surge uma nova perspectiva, os eventos que se manteram ainda movimentam uma alta demanda turística e incrementa a economia local. Um grande exemplo é o Folianópolis, micareta de Florianópolis/ Santa Catarina, que apresenta uma nova forma de fazer o evento. A preocupação em inovar é perceptível até em seu formato, que se diferencia das demais através de sua conceituação temática, proporcionando novas vivências e a experimentação a um público cada vez mais exigente.

\section{Criatividade em Eventos}

A pesquisa e a implementação da criatividade, como ferramenta capaz de gerar um produto ou serviço diferenciado, tem ganhado respaldo e cada vez mais aplicabilidade. No campo dos eventos não é diferente e muito tem acrescido no planejamento e execução desses.

Dias e Pimenta (2005) apontam que - novas ideias e lugares para eventos surgem todos os dias. Para essas ideias se concretizarem são necessários: planejamento, organização, execução e avaliação de cada etapa do evento. Ou seja, a criatividade é algo que deve estar inserida não apenas no produto, mas em todo o processo de organização do evento.

A criatividade surge como algo que faz ir além, e, associadas aos eventos, mostra-se como um novo campo experimental, com novas oportunidades de criação e recriação, de modo que as intempéries da vida moderna são esmiuçadas e debatidas de forma mais suave por intermédio de eventos que utilizam diferentes estéticas e linguagens (Melo Neto, 2013).

Ao iniciar essa discussão, faz-se importante revelar os benefícios proporcionados ao participante, uma vez que, de maneira tradicional ou inovadora, há anseios que permeiam as motivações de se fazer presente num evento.

Panosso e Gaeta (2010) dizem que fazer eventos passou a ser uma atividade impregnada de aspectos subjetivos. A experimentação passou a ser uma característica demandada e, apesar de ser composto de elementos tangíveis, o intangível passou a despontar como o diferencial procurado.

Para chegar-se a esse patamar de experiência promovida, Melo Neto (2013) revela que o caminho a ser seguido é agregar valor através do entretenimento, posto que "um evento, independente de sua natureza e seus propósitos, é um meio de entretenimento" (Melo Neto, 2013 p. 15). Desse modo, observa-se que investir em ações ligadas ao entretenimento resulta 
num grau de experiência superior aos proporcionados por um único segmento, fazendo com que a diversão seja promovida a fator determinante de compra.

Seguindo a evolução, o novo fazer em eventos busca rever padrões e redesenhá-los a contemporaneidade. Ao transpor limites, os criadores de eventos diversificam as possibilidades de ações e atividades, uma maneira de criar padrões e de inserir elementos distintos como um novo padrão estético, novas ferramentas de entretenimento, novos cenários, nova iluminação, novas cores, novo movimento, novas tecnologias e, assim, promover a experimentação.

A exposição acima representa um caminho inovador de fazer eventos, que engloba da concepção ao pós- evento. Desmitificado a tendência a experimentação, o valor do entretenimento e as necessidades do usuário dos eventos, chega-se ao ponto de esclarecer como ocorre o processo criativo e inovador em eventos.

Apesar de bastante disseminada a premissa que a criação criativa está livre de amarras e padrões, é fato que o processo de inovação necessita de um direcionamento para que boas ideias sejam transformadas em rentáveis respostas.

Ao buscar esclarecer a significação das estratégias criativas aplicadas a eventos, iniciase uma discussão acerca de valor agregado e o que isso reflete nesse setor. Já é sabido que a concorrência é algo crescente no mercado e que a previsão confirma que, cada vez mais, estratégias diferenciadas deverão ser buscadas com vistas à construção de uma vantagem competitiva.

O valor agregado integra esse grupo de ações voltadas a incrementar a experiência do cliente ao produto/serviço. Trata-se, então, de tudo aquilo que vem agregado ao produto/ serviço e que leve ao cliente atender suas necessidades, considerando os benefícios e os preços em relação à concorrência.

Rados, Valerim e Blattmann (1999, p. 205) conceituam o valor agregado ao serviço ou produto como "o reconhecimento do benefício alcançado pelo cliente versus o recurso empregado para realizar uma atividade ou ainda o incremento de facilidade para atender uma necessidade ou para resolver um problema". Para tal, é necessário estar com o foco voltado ao cliente, entender suas vontades, suas mudanças, seus hábitos, suas prioridades e seus valores.

Alguns elementos são apontados como tendências em eventos criativos, dentre tais, Cordeiro (2017) ${ }^{1}$ destaca os abaixo elencados.

${ }^{1}$ Notícia fornecida por Rodrigo Cordeiro no $8^{\circ}$ Fórum de Turismo do RN, em Natal, em abril de 2017. 
A sustentabilidade é a palavra de ordem em todas as camadas da sociedade. Ser sustentável é aproveitar os elementos disponibilizados pela natureza sem comprometer futuras gerações. O uso consciente dos recursos é cada vez mais utilizado na gestão de eventos através de estratégias que reduzam o consumo, diminuam a poluição e os impactos ambientais.

A customização de bens, serviços e experiências também é um grande diferencial aplicado aos eventos. Ao identificar o público-alvo, seus interesses e objetivos é possível direcionar ações e produtos personalizados, assim promove-se a diferenciação e o valor agregado.

Com a elaboração de layouts diferenciados cria-se uma atmosfera propicia a integração e a interação. Esse modelo precisa estar alinhado as ações e as experiências que pretende promover, estimulando a integração e diversificando as maneiras de apresentação.

As redes sociais despontam como, talvez, a maior ferramenta inovadora, isso porque sua aplicação em eventos serve como instrumento de marketing, por parte da organizadora, como do participante, uma vez que a publicação nas redes sociais, seja por fotos, checkins ou transmissões simultâneas, tem seu poder de incentivar na decisão do cliente potencial.

Atenta-se que a criatividade não é uma competência nata e pode ser desenvolvida e aprimorada. Também ressalta-se que, apesar da existência de moldes que norteiam e facilitam o processo criativo, a ideação também ocorre por meio de insights, promovido por fatores denominados de expertise, engloba características dos indivíduos voltadas à área de atuação, a destacar o talento, o conhecimento, a experiência e as habilidades técnicas; a motivação intrínseca, uma vez que as pessoas são mais criativas quando se sentem motivadas, principalmente, pelo interesse, pelo gozo, pela satisfação e pelo desafio da própria obra; e as habilidades criativas de cada indivíduo (Amabile, 2012).

Entende-se que o processo criativo, como um todo, e voltado aos eventos, é composto por vetores capazes de motivar o pensar criativo, mas torna-se pertinente considerar as distintas características individuais dos produtores, as condições ambientais do local do evento, o perfil da demanda, os recursos disponíveis, o objetivo do evento e outros elementos que agem diretamente sobre o resultado criativo. 


\section{METODOLOGIA}

A pesquisa científica é o meio mais concreto de obtenção de respostas a questionamentos teóricos ou práticos e de alcance de soluções para problemas. No âmbito do turismo, o aprimoramento da pesquisa permite a evolução do fenômeno turístico em várias vertentes (Dencker, 1998).

Ao considerar o objetivo geral, a presente pesquisa mostra-se como um estudo descritivo que, segundo Gil (2009), intenciona retratar o perfil de uma população peculiar ou de um fenômeno particular e, exploratório, que permite, através de estratégias de investigação, aproximar-se do problema inquirido.

Com uma abordagem qualitativa "por ser uma forma adequada de entender a natureza de um fenômeno social" (Richardson, 1999, p. 79) e possibilitar uma imersão no âmbito em que o problema se desenvolve, a inquirição aqui desenvolvida buscou alinhar a subjetividade e a empiria, resultando numa convergência de teorias e praticas na obtenção de respostas ao problema proposto.

Considerando complementar a pesquisa e alicerçado nos procedimentos técnicos empregados, a investigação aqui exposta apresenta-se como um estudo de caso, que segundo Yin (2010, p. 23) é "um dos empreendimentos mais desafiadores na pesquisa", uma vez que para sua aplicação exige um alto grau de imersão do pesquisador.

Diante da diversidade de micaretas brasileiras, o Carnatal foi determinado como representação dessa modalidade de eventos turísticos e que, por sua vez, possui a Destaque Promoções como promotora do festival. A referida organização dispõe de um quadro funcional flexível, composto por colaboradores formais, informais e terceirizados que chegam a alcançar um número próximo a três mil, englobando todas as fases do evento. No entanto, para a presente pesquisa, o foco foi direcionado aos funcionários que possuem vínculo formal durante todo o ano.

Ao buscar compreender o processo criativo, que inicia-se dentro da empresa promotora e reverbera na realização do evento, foram definidos como atores da pesquisa os colaboradores que estão em hierarquia abaixo dos diretores, acrescentando, o diretor de marketing, por ser o setor em que é mais fortemente empreendida ações de criação; e o diretor de produção, também um dos fundadores da empresa.

Como instrumentos de coleta de dados utilizou-se, inicialmente, da pesquisa documental e bibliográfica que permitiu traçar todo o histórico e evolução do Carnatal. Com 
vista a complementar os dados, foi efetivada uma entrevista semiestruturada com dois, dos quatro diretores da organização.

A observação não participante, essencial devido à propriedade com que penetra na complexidade de um problema (Richardson, 1999), foi implementada em dois momentos distintos. Dentro da Destaque Promoções, iniciou-se no dia 26/10/17 e estendeu-se até a 01/12/17 e possibilitou o acompanhamento da rotina organizacional, identificando os elementos promotores e entraves a criatividade. Durante quatro horas diárias, a autora utilizava-se de um diário de observação para fazer às anotações pertinentes a pesquisa e aos questionamentos aleatórios que surgiam de acordo com a rotina de trabalho.

Os pontos observados foram embasados nas dimensões da criatividade: encorajamento organizacional, encorajamento do supervisor, suporte do grupo de trabalho, recursos suficientes, trabalho desafiador, liberdade, impedimentos organizacionais e pressão. Inserirse na organização e acompanhar o desenvolvimento das mais diversas ações foi esclarecedor e fundamental para cobrir pontos obscuros.

Em um segundo momento, a observação foi realizada no próprio evento, que ocorreu entre os dias 07 e 10/12/2017. Circular pelos diversos espaços elaborados, blocos; camarotes particulares; camarote Skol; arquibancada e arena elétrica, durante os quatro dias de Carnatal, viabilizou a identificação de diferenciais criativos e inovadores da vigésima sétima edição do evento.

Os dados levantados foram submetidos a uma análise pelo software qualitativo NVIVO, devido a sua propensão a colaborar na estruturação e na tradução dos dados, além de possuir a capacidade de indexar e de gerir o conteúdo armazenado em seu banco de dados (Veal, 2011).

Com os resultados, alinhou-se as teorias que os subsidiaram para, assim, submetê-los à análise de conteúdo, já que Bardin (2011) retrata que tal procedimento é um agregado de elementos metodológicos cada vez mais ameno, inserido num processo contínuo de evolução a aplicar-se aos discursos vastamente variados. A autora ainda acresce que "tal processo oscila entre dois polos do rigor da objetividade e da fecundidade da subjetividade" (Bardin, 2011, p. 15). Enfim, os resultados alcançados serão apresentados e discutidos na seção a seguir. 


\section{ANÁLISE E DISCUSSÃO DOS RESULTADOS}

O Carnatal, realizado em Natal/Rio Grande do Norte, possui um histórico que demonstra bem o processo de reformulação do evento, uma vez que, nos quase vinte e oito anos de realização, fez-se importante a utilização de estratégias que o adaptasse as mudanças ambientais e legais, além das transformações comportamentais da demanda.

O evento surgiu em 1991 e foi realizado no centro de Natal com apenas três blocos e doze camarotes. À medida que os anos passaram, esse número evoluiu até alcançar a marca de cento e vinte camarotes e seis blocos, no ano de 1993. No ano seguinte, o espaço ficou pequeno para a proporção do evento, que foi transferido para o largo do antigo estádio de futebol da cidade, o Machadão.

Com nova localização, o Carnatal teve a oportunidade de expansão e atingiu um número de quinhentos e vinte cinco camarotes e quatorze blocos. Em referência a grandiosidade, foi em 1997 que o evento alcançou o auge em relação a seu tamanho, trazendo dezenove blocos na ocasião.

Ainda com um formato outdoor, que tanto atingia um público pagante, com seu espaço de entretenimento delimitado por cordas, como aqueles que usufruíam da festividade de forma gratuita, pulando num setor sem cordas denominado pipoca, chegou a atingir um público estimado em um milhão de participantes, nos quatro dias de festa.

Com a seleção da capital potiguar como uma das sedes para a Copa do Mundo de 2014, algumas mudanças foram necessárias à adaptação desse novo contexto. Após as obras de demolição do Machadão iniciadas, na edição de 2011, o percurso foi adaptado e restringido a configuração do local. Já em 2013, o evento teve seu local de realização alterado para o Parque Aristófanes Fernandes, em Parnamirim, sendo essa a primeira e, até então, a única vez que não foi sediado no município de Natal.

Em 2014, com as obras no entorno do Arena das Dunas concluídas, o Carnatal firmouse na área de eventos do estádio, transformando-se, então, num evento indoor até os dias atuais.

O objeto de estudo da presente pesquisa, produz benefícios perceptíveis nos quatro dias de realização e nos demais dias do ano, uma vez que além de diminuir a sazonalidade, amplia a alta temporada, por sua realização ser efetivada em período que antecede esta. Deste modo, dialoga com o que é preconizado por Derrett (2003) ao afirmar que promoção de eventos é capaz de estender temporadas turísticas, de ampliar o ápice dessas ou, até mesmo, de incluir uma nova temporada a um circuito turístico. 
Uma pesquisa realizada com um público respondente de aproximadamente 800 pessoas, na cidade de Natal, em 2017, pelo Perfil Pesquisa Técnicas e com a intenção de analisar a marca Carnatal, demostra que $95,87 \%$ dos entrevistados conhecem o evento; $32 \%$ o apontam como o maior evento da cidade e $76,37 \%$ reconhecem o impacto positivo dele sobre o turismo e a economia local.

Além disso, 86,49\% afirmam que o Carnatal é capaz de divulgar e promover a cidade de Natal por todo o Brasil, fortalecendo a teoria apontada por Getz (1997) que revela os eventos com papel fundamental na elaboração de uma imagem positiva do destino, pois concilia atrações adicionais e valoriza o local de manifestação turística. E, ao questionarem aos respondentes sobre quais são os atrativos mais lembrados da capital potiguar, a praia de Ponta Negra e o Carnatal aparecem, respectivamente, nos primeiros lugares.

Ademais, dados levantados com a Associação Brasileira da Indústria de Hotéis do RN - ABIH/RN, afirmam o impacto positivo do evento sobre o trade turístico, especificamente na rede hoteleira, ao demonstrar que em 2015 a ocupação chegou a 70,5\% e em 2017, a 81,9\%, atestando assim o discurso de Beni (2003) que aponta a efetivação de eventos, no campo do turismo, como uma ferramenta promotora da atratividade turística, equilibrando a sazonalidade, movimentando uma demanda em locais de pouca atratividade e ampliando o uso da estrutura básica e turística da localidade receptora.

Por trás de todo esse espetáculo está a engrenagem que movimenta o planejamento e garante a efetivação do Carnatal, a Destaque Promoções. A empresa foi fundada pelos amigos Ricardo Bezerra, Roberto Bezerra, Gustavo Carvalho e Paulinho Freire e iniciou no mercado atuando com marketing, propaganda e promoção de eventos. Anos depois, empreenderam em uma ideia precursora, a realização de uma Micareta na cidade de Natal (RN), que passou a ser o elemento mais importante do seu portfólio.

Depois de trinta anos no mercado e mais de três mil eventos realizados, o Carnatal continua sendo o carro chefe da organização e, mesmo diante da repercussão da crise do axé music, título dado ao conjunto de ritmos e danças baianas, sendo esse o vetor que conduzia exclusivamente o evento, o Carnatal ainda permanece como um produto turístico valorizado.

Para auferir visibilidade e continuar cativando novas gerações de clientes, a Destaque Promoções precisou buscar uma nova forma de gestão que trouxesse resultados esperados. $\mathrm{O}$ desafio de gerir eventos no contexto atual pede por estratégias inovadoras e, para tal, a organização precisa contar com recursos específicos para promover o comportamento criativo, desenvolvendo fatores que podem influenciar positivamente a criatividade organizacional e a consequente inovação. 
Verificou-se um alto grau de aprovação no que concerne ao encorajamento de ideias, ao reconhecimento das pessoas e as recompensas oferecidas. $\mathrm{O}$ incentivo a criação de novas ideias é percebido à medida que se observa a liberdade de criação dada a cada colaborador. $\mathrm{O}$ resultado desse processo é levado à discussão e à análise de viabilidade, partilhada por todos os setores da organização. Um ponto a ser destacado é que não há uma restrição quanto ao conteúdo do que é proposto, desde que seja condizente com a realidade financeira e atenda ao proposito solicitado.

$\mathrm{O}$ reconhecimento dado as pessoas concretiza-se à medida que se promove a indispensabilidade do indivíduo para a organização, algo que é partilhado e reforçado, rotineiramente, com o intuito de elevar a motivação do colaborador que responde com projetos mais criativos. Os dados coletados expõem o alto sentimento de confiança e de solidariedade existente entre o grupo, o que representa um vetor de ideação. Essa confiança tem efeitos positivos em atitudes, percepções, comportamentos e desempenho dentro das configurações organizacionais.

A Destaque Promoções disponibiliza os insumos necessários ao desenvolvimento de projetos facilitando a criação, já que a alocação adequada de recursos está diretamente relacionada aos níveis de criatividade dispensados ao trabalho desenvolvido. A satisfação é perceptível dentro da empresa devido aos orçamentos adequados aos projetos. Os investimentos próprios, ou resultados de parcerias, são aplicados coerentemente no desenvolvimento e na implementação dos trabalhos aprovados. Até mesmo na ausência de produtos, equipamentos ou serviços, esses são trazidos, sem esforços, de outras cidades ou estados, para garantir o diferencial e a inovação do evento realizado.

Por fim, constatou-se o devido alinhamento entre a criatividade estimulada dentro do ambiente organizacional e os elementos inovativos identificados no evento. Uma equipe devidamente preparada e criativa que consegue converter em soluções e adequações criativas, corroborando para a ampliação e sucesso do evento.

Em última análise, foi possível comparar edições passadas do Carnatal, quando ainda possuía um formato outdoor, que por sua grandiosidade, revelava-se como um evento com alta capacidade de atração, com a edição do ano de 2017, em que, num formato indoor, precisou reinventar-se e propor novas ações de atração do público.

Projetar um evento um espaço delimitado e consideravelmente menor exige uma pesquisa avançada e a implementação de estratégias criativas que captem um novo público, pessoas mais jovens que estão descobrindo o evento em questão, e mantenha os foliões antigos, que vivenciaram todo o esplendor de áureos tempos da micareta. 
Para a edição de 2017, além das arquibancadas, local de preço mais acessível e que permite visualizar todos os blocos e artistas, os blocos que continuam a ser o elemento chave do evento, com artistas renomados do axé music e outros estilos musicais que passaram a fazer parte do evento e assim diversificando a ofertas. O trajeto percorrido pelo folião dos blocos, nessa edição, é de aproximadamente três quilômetros, sendo 450 metros de Corredor da Folia, com arquibancadas e ala de camarotes. Os blocos passam duas vezes pelo corredor, dando duas voltas no percurso e totalizando cerca de quatro horas de folia.

Surgiu também dois novos componentes, a arena elétrica, local de encontro ao final do evento de todos os participantes onde ocorria uma show de encerramento com artistas renomados nacionalmente, em um trio moderno chamado de Pranchão que proporciona maior interação artista/público. O espaço foi composto por segurança, estrutura de banheiros, bares e food trucks com acesso garantido para o folião presente em qualquer área da micareta. Sendo, nesse ano, ainda possível a compra somente para esse setor, uma forma de tentar incorporar a antiga pipoca ao evento.

De todos os setores, aquele que, visivelmente, sofreu uma maior transformação, foi o camarote Skol Beats, setor privado com valor mais elevado que os demais. Tratou-se de um espaço desenhado com o intuito de levar a experimentação ao usuário. Além da visualização de todos os blocos, o folião podia desfrutar de shows exclusivos nesse espaço. Local de descontração, diversidade, visão privilegiada dos trios e dos blocos, ainda dispôs de serviço open bar. Os espaços de relaxamento e bem estar foram os diferenciais do camarote, além da decoração e iluminação diferenciada. Literalmente, a festa dentro da festa.

Constata-se então, veracidade e respaldo ao que defende Melo Neto (2013), em que a criatividade emerge como algo que proporciona a superação de limites, um fazer diferenciado que vai de encontro aos anseios do público. Mostra-se como um novo campo experimental, com novas oportunidades de criação e recriação, de modo que as intempéries da vida moderna são esmiuçadas e debatidas de forma mais suave por intermédio de eventos que utilizam diferentes estéticas e linguagens. 


\section{CONSIDERAÇÕES FINAIS}

Organizar um evento é mergulhar num universo de possibilidades e combinações. É um olhar voltado ao contratante e para o usuário do evento. É unir conhecimento, experiência, empatia, dinamismo, proatividade, eficiência e tantas outras características em um único grupo. É orquestrar ações para alcançar o sucesso no final e isso não significa apenas um grande retorno de divisas, mas a satisfação de ter realizado um evento diferenciado, que marcará positivamente a memória dos usuários.

Entende-se que o Carnatal é um evento grandioso e de sucesso por basear-se em sua tradição, no entretenimento e na falta de concorrentes diretos. Para além, o seu formato corrobora com o que é preconizado por Melo Neto (2013) ao apontar o entretenimento como forma de valorização do evento. Trata-se, então, de uma celebração cativa no calendário de micaretas do Brasil e que gradativamente vem apresentando inovações incrementais não orientadas por estratégias de inovação da organização, mas para fornecer respostas aos problemas que emergem além da empresa, como, por exemplo, a mudança de local de realização do evento e do seu formato.

Muitos foram os obstáculos encontrados na trajetória de execução do Carnatal, momentos de incertezas e até mesmo de fracasso, como o ocorrido na edição de 2013, quando tiveram que transferir o tradicional evento natalense para a cidade de Parnamirm. Esse foi um momento que fez com que a empresa organizadora questionasse a continuidade do evento, algo que logo foi superado devido à paixão dos quatro diretores pela micareta, uma paixão que reverbera em toda a organização.

O turismo de eventos muito se beneficia com a realização anual do evento, todo o trade turístico local é atingido de forma positiva, à marca da cidade Natal é disseminada, o que leva a entender que o Carnatal vai além do lucro gerado para a organização. Parcerias com órgão governamentais devem ser fortalecidas e relações com outras entidades, como Convention Bureau e FECOMÉRCIO, precisam ser estreitadas. Desse modo, os benefícios são estendidos alcançando o turista, o morador local e a cidade como um todo.

Sugere-se para pesquisas futuras acrescer a percepção do usuário turista quanto ao grau de criatividade percebido e quanto isso é capaz de diferenciar e transformar o evento num produto turístico de sucesso. 


\section{REFERÊNCIAS}

Amabile, T. M. (2012).Componential Theory of Creativity. Harvard Business School Working Paper.

Bardin, L. (2011). Análise de conteúdo. São Paulo: Edições 70 Brasil.

Beni, M. C. (2003). Análise estrutural do turismo. São Paulo: Editora Senac.

Bowen, H., \& Daniels, M. (2005). Does the music matter? Motivations for attending a music festival. Event Management, 9, 155-164.

Britto, J., \& Fontes, N. (2013). Estratégias para eventos: uma ótica do marketing e do turismo. São Paulo: Aleph.

Connel, J., Page, S.J., \& Meyer, D. (2015). Visitors attractions and events: responding to the seasonality. Tourism Management, 46, 283-298.

Csikszentmihalyi, M. (1990). The Psychology of Optimal Experience. Journal of Leisure Research, 24, 93-94.

Dencker, A. F. (1998). Métodos e técnicas de pesquisa em turismo. São Paulo: Futura.

Derrett, R. (2003). Festivals, events and the destination. In: I. Yeoman, M. Robertson, J. AliKnight, S. Drummond, \& U. Mcmahon-Beattie (Eds.). Festival and events management: an international arts and culture perspective. Oxford: Elsevier Butterworth Heinemann.

Dias, R., \& Pimenta, M. A. (2005). Gestão de Hotelaria e Turismo. São Paulo: Pearson Prentice Hall.

Gaudin, B. (2000). Da mi-carême ao carnabeach: história das micaretas. Tempo Social Revista de Sociologia da USP, 12, 47-68.

Getz, D. (1997). Event Management \& Event Tourism. New York: Cognizant Communication Corporation.

Getz, D., \& Page, S. J. (2016). Progress and prospects for event tourism research. Tourism Management, 52, 593-631.

Gil, A. C. (2009). Como elaborar projetos de pesquisa. São Paulo: Atlas.

Melo Neto, F. P. (2013). Criatividade em Eventos. São Paulo: Contexto.

Moital, M., \& Gândara, J. (2012). Sensual Tourism in Brazil: the Off-Season Carnival. In: G. Lhomann, \& D. Dredge (Eds.). Tourism in Brazil: Environment, Management and Segments (pp. 140-157.) London: Routledge.

Panosso, A. N., \& Gaeta, C. (2010). Turismo de Experiência. São Paulo: Senac.

Pinto, F. C., \& Jesus, L. A. (2010). Micareta de Feira de Santana: uma festa popular sob o olhar das relações sociais e socioeconômicas. ReAC - Revista de Administração e Contabilidade, 2(2), 35-50.

Rados, G. J., Vlerim, P., \& Blattmann, Ú. (1999). Valor Agregado a Serviços e Produtos de Informação. Informativo $C R B$ 14/ACB, 9, 11-12. 
Richardson, R. J. (1999). Pesquisa social: métodos e técnicas. (3a. ed.). São Paulo: Atlas.

Xavier, C. V., \& Maia, C. E. (2010). Vira, virou a micareta emplacou! História Revista, 15, 323-340.

Veal, A. J. (2011). Metodologia de pesquisa em lazer e turismo. São Paulo: Aleph.

Yin, R. K. (2010). Estudo de caso: planejamento e métodos. (4a. ed.). Porto Alegre: Bookman.

BRITO, G. C. \& FERREIRA, L. V. F. (2019). Carnatal: A criatividade como ferramenta propulsora do turismo de eventos. Revista de Turismo Contemporâneo, 7, Edição Especial, 47-68. https://doi.org/10.21680/2357-8211.2019v7n0ID16985 